International Journal of Applied Research 2021; 7(10): 203-207

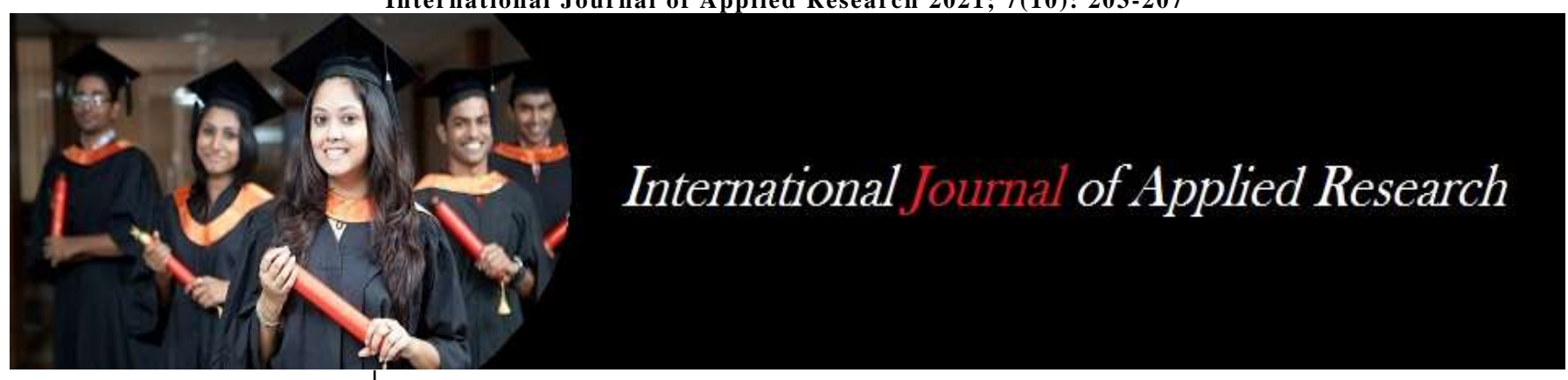

ISSN Print: $2394-7500$

ISSN Online: 2394-5869

Impact Factor: 8.4

IJAR 2021; 7(10): 203-207

www.allresearchjournal.com

Received: 12-07-2021

Accepted: 21-08-2021

\section{अविनाश कुमार}

शोध छात्र, स्नातकोत्तर समाजशास्त्र विभाग, मगध विश्वविद्यालय, बोधगया, बिहार, भारत
Corresponding Author: अविनाश कुमार

शोध छात्र, स्नातकोत्तर समाजशास्त्र विभाग, मगध विश्वविद्यालय, बोधगया, बिहार भारत

\section{विज्ञापन का इतिहास और विकास}

\section{प्रस्तावना:}

विज्ञापन का इतिहास मानव सभ्यता के विकास के साथ ही जुड़ा है। आदिकाल से वर्तमान तक के वैज्ञानिक युग में मानव किसी न किसी रूप में कम या अधिक अपनी आवश्यकताओं के अनुसार विज्ञापन पर निर्भर रहा है। सभ्यता के विकास के साथ-साथ संचार माध्यम बदलते रहे हैं। उन्हीं माध्यमों के सहारे विज्ञापनों का स्वरूप भी बदलता रहा है। विज्ञापन के इतिहास का अध्ययन हम प्राक्-ऐतिहासिक काल की चित्रकला के अध्ययन से करें तो उसमें ऐसे अनेक उदाहरण मिलते हैं जिनमें चित्रों द्वारा, चिन्हों द्वारा, डुग-डुगी बजाकर मानव अपने विचारों की अभिव्यक्ति करता था। इन्हीं चित्रों एवं चिन्हों से ही लिपि का विकास हुआ। लिपि वृहद सम्प्रेषण के लिये मानव सभ्यता का सबसे प्रभावी माध्यम बनी। विभिन्न शासकों ने अपनी घोषणाएं शिलालेखों पर लिखवाई, जो उस समय के अनुसार किसी न किसी रूप में ' विज्ञापन कला' का ही स्वरूप था। हमारे आदि ग्रन्थ 'रामायण' और 'महाभारत' में भी इस प्रकार के उदाहरण मिलते हैं जो एक तरह के तात्कालिक युग के विज्ञापन कहे जा सकते हैं। अनेक राजाओं द्वारा उद्घोषक नियुक्त किये जाते थे। राजाओं द्वारा दी जाने वाली सूचनाओं को पूरे राज्य में प्रसारित किया जाता था, जिसका सुधरा हुआ स्वरूप आज विज्ञापनों में देखने को मिलता है।

प्राचीन काल में किसी-न-किसी प्रकार की संचार व्यवस्था रही है। बहुत पहले भी वस्तुओं पर ट्रेडमार्क का उल्लेख मिलता है। उस समय हाथ से वस्तुएँ तैयार की जाती थी। उन वस्तुओं पर कोई-न-कोई चित्र बना दिया जाता था। इसका कारण यह था कि उसके उत्पाद को पहचानने में उपभोक्ता को आसानी हो। विज्ञापन का आरम्भिक रूप पाम्पई में मिले हैं। उन प्राप्त अवशेषों से पता चलता है कि दुकानों में प्रवेश के आस-पास कुछ चिन्ह अंकित कर दिए जाते थे ताकि यह पता चल सके कि दुकान में कौन-कौन सी वस्तुएं उपलब्ध हैं। सभ्यता के विकास के साथ इन्हीं चिन्हों को लकड़ी, धातु या पत्थर के पटों पर लिखकर दुकान पर लगाया जाता होगा। आज जो सूचना पट्ट होर्डिंग इत्यादि जो लगाया जाता है, वह उसी का विकसित रूप है।

आवश्यकता को प्रकट करने के लिए अभिव्यक्ति या संचार की जरूरत पड़ती है। ईसा पूर्व चित्रों और कलाकृतियों के माध्यम से अभिव्यक्ति का काम लिया जाता था। मंदिरों, र्मारकों, पिरामिडों पर अंकित चित्रकला विश्व की अनेक सभ्यताओं को अभिव्यक्त करता है। शिलालेख भी इसी श्रृंखला की कड़ियां हैं। विज्ञापन का प्रारम्भिक रूप मौलिक सन्देश सम्प्रेषण के रूप में मिलता है। लिपि का विकास होने के पूर्व राजकीय घोषणाएँ, उद्घोषकों, ढोल-नगाड़े बजाकर सूचनाएं प्रेषित करने की परम्परा थी। आज भी भारत के ग्रामीण क्षेत्रों में एवं आदिवासी क्षेत्रों में विज्ञापन के इस रूप को देखा जा सकता है। प्राचीनकाल में अश्वमेघ यज्ञ और स्वयंवर रचाने का कार्य भी विज्ञापन के हीं प्राचीन रूप कहे जा सकते हैं।

ईसा से सैंकड़ों वर्ष पूर्व यूनान में दास-प्रथा का प्रचलन था। राजा जनता के मनोरंजन के लिए दासों का युद्ध करवाते थे। जब दास की मृत्यु हो जाती थी तब विजय-पराजय की घोषणा होती थी। इन आयोजनों को देखने के लिए डुगडुगी बजाया जाता था ताकि हजारों लोग इस कार्यक्रम को देख सकें। यही तो विज्ञापन है।

विज्ञापन के प्रारंभिक चरण में विक्रेता ऊंची आवाज में बड़े रोचक और नाटकीय अंदाज में अपने माल की खूबियों को वर्णित करता था। यानी गलियों और सड़कों पर फेरीवाले आवाज लगाते हुए अपनी वस्तुओं का विज्ञापित करते थे। बाद में चना बेचनेवालों के ये बोल बहुत चर्चित भी हुए- 'बाबू मैं लाया मजेदार चना जोर गरम, मेरा चना बना है आला..' अनोखे स्वरों द्वारा अपने माल को विज्ञापित कर खरीदारों को आकर्षित करने की यह कला आज भी बनी हुई है। गांवों, कस्बों और शहरों की गलियों में ठेले और साइकिल पर अपना सामान बेचने वाले छोटे-छोटे विक्रेता इसी कला का सहारा लेते हैं। 
विज्ञापन के इतिहास का प्रारंभ पंद्रहवीं शताब्दी में मुद्रण कला के आविष्कार के साथ हुआ। नए विचारों के प्रवाह को जन-जन तक पहुंचाने के लिए मुद्रण कला का सहारा लिया गया। यद्यपि मुद्रण कला का सूत्रपात चीन में हुआ। इतिहासकार आधुनिक मुद्रण कला का श्रेय पश्चिमी जर्मनी के गुटनबर्ग को देते हैं। गुटनबर्ग ने 42 पंक्तियों की विश्व की पहली मुद्रित पुस्तक 'बाइबिल' का प्रकाशन किया। मुद्रण कला के आविष्कार और विस्तार के साथ ही यातायात व संचार के विभिन्न साधन भी उपलब्ध हुए। जनमत को प्रभावित करने के लिए मुद्रण कला का व्यावहारिक रूप सामने आया। पहला मुद्रित विज्ञापन कैसा है, इस बारे में मतभेद है। कुछ लोग मानते हैं कि सन् 1473 ई. में इंग्लेंड में विलियम कैक्टसन ने सर्वप्रथम अंग्रेजी भाषा में पहला विज्ञापन एक परचे के रूप में प्रकाशित किया। लेकिन इतिहासकार फ्रेंक प्रेस्वी के अनुसार- 'मक्यूरियम ब्रिटानिक्स' पुस्तक में एक विज्ञापित घोषणा के रूप में विज्ञापन का पहला रूप सामने आया। हेनरी सैंपसन के अनुसार- सन् 1650 में सर्वप्रथम विज्ञापन का स्वरूप एक पुस्तक में देखने को मिला, जिसमें चोरी किए गए बारह घोड़ों को लौटाने पर पुरस्कार की घोषणा विज्ञप्ति के रूप में छपी थी। विज्ञापन की ऐतिहासिक पृष्ठभूमि इंग्लैंड के समाचार-पत्रों में विज्ञापन के रूप में प्रकाशित घोषणाओं में दिखाई देती है। उसके बाद चाय, कॉफी, चॉकलेट, किताब आदि के विज्ञापनों के साथ-साथ खोई-पाई वस्तुओं के विज्ञापन प्रकाशन की प्रथा चल पड़ी।

अमेरिका में विज्ञापन का विकास बड़ी तीव्र गति से हुआ। विजय कुलश्रेष्ठ और प्रतुल अथइया के अनुसार-सन् 1870 में अमेरिका में पहला विज्ञापन प्रकाशित हुआ था, जो उस काल की बीज कंपनियों (सीड्स कंपनीज) की पहल कहा जाता है, लेकिन प्राप्त जानकारियों के अनुसार अमेरिका में सन् 1841 में पहली विज्ञापन एजेंसी वाल्नी पॉल्मर स्थापित हो चुकी थी। अमेरिका का पहला विज्ञापन 8 मई, 1704 में 'बोस्टन न्यूज लैटर' में प्रकाशित हुआ। धीरे-धीरे सचित्र विज्ञापन की प्रथा भी शुरू हो गई। विज्ञापन में आधुनिक तकनीक का प्रयोग किया जाने लगा। औद्योगिक क्रांति के फलस्वरूप विज्ञापन की दुनिया में तेजी से बदलाव आने लगा। अब विज्ञापन उद्योग एक आकर्षक उद्योग बन चुका है। प्राचीन काल से ही अन्य सभ्यताओं की तरह ही भारत में भी विज्ञापन का किसी न किसी रूप में अस्तित्व रहा है। हमारे प्राचीन ग्रन्थों में भी ढोल बजाकर, चिल्लाकर या डुग-डुगी बजाकर उद्घोषणा करने के प्रमाण मिलते हैं। सिन्धुघाटी की सभ्यता से प्राप्त प्रमाणों में भी चिन्हों, मोहरों और लिपि के प्रमाण प्राप्त हुए हैं। इन मोहरों या चिन्हों का स्वरूप आधुनिक प्रतीक चिन्हों या लोगों टाइप से मिलता-जुलता है। ईसा पूर्व की लगभग ढाई-तीन हजार वर्ष पूर्व की प्राचीन सभ्यता के नगरों, हड़प्पा और मोहन जोदड़ो से प्राप्त अवशेषों में भी कलात्मक वस्तुएं और मोहरें प्राप्त हुई हैं जो एक तरह से व्यापारिक चिन्ह आदि के रूप में विज्ञापन ही रहा होगा। मौर्यकाल में भी सम्राट अशोक द्वारा स्थापित स्तम्भों का निर्माण बौद्ध धर्म के प्रसार के लिए किया गया था जिनमें ब्राह्मी लिपि में संदेश होते थे। इन स्तम्भों के संदेशों में बौद्ध धर्म के प्रसार के लिए की गई घोषणाएं हैं जो आधुनिक विज्ञापन का ही रूप हैं। जिस प्रकार से मुद्रण के आविष्कार ने अन्य देशों में विज्ञापन को प्रोत्साहन दिया उसी तरह भारत में भी विज्ञापन के लिए मुद्रणकला का महत्वपूर्ण योगदान रहा है। भारत में सर्वप्रथम मुद्रण मशीन 6 सितम्बर 1556 में संयोगवश ही आ गई। इस मुद्रण मशीन को पुर्तगाल से गोवा होते हुए अबीसीनियां भेजा जाना था। राजनैतिक कारणों से इस मशीन को गोवा में ही रोक लिया गया और गोवा में प्रथम मुद्रण मशीन की स्थापना हुई जिससे प्रथम पुस्तक दौक्त्रीना क्रिस्ताओ का प्रकाशन किया गया। भारत में दूसरी मुद्रण मशीन 1674-75 ई. में स्थापित की गयी जिसे गुजरात के व्यापारी भीमजी पारिख ने इंग्लैण्ड से मंगवाया था। इसके बाद लगभग
1712 में मद्रास में तीसरी मुद्रण मशीन की स्थापना की गयी। उपरोक्त सभी मशीनों की स्थापना ईसाई मिशनरियों द्वारा धर्मप्रचार के उद्देश्य के लिए की गई थी।

29 जनवरी 1780 को जेम्स आगस्ट हिक्की ने कलकत्ता (कोलकाता) में पहला समाचार-पत्र बंगाल गजट (हिक्की गजट) प्रकाशित किया। सन् 1784 से कलकत्ता गजट का प्रकाशन प्रारम्भ हुआ। सन् 1786 तक कलकत्ता (कोलकाता) में चार साप्ताहिक समाचार पत्र और पत्रिकाएं छापे जाने लगे थे। बंगाल गजट नामक समाचार पत्र में सरकारी विज्ञापन मुफ्त छपते थे। सन् 1790 से बम्बई में द कोरियर नामक समाचार पत्र का प्रकाशन प्रारम्भ हुआ जिसमें सर्वप्रथम भारतीय भाषाओं- उर्दू, गुजराती, मराठी आदि भाषाओं में विज्ञापन छापे गये। सन् 1816 में अमेरिकी ईसाई मिशनरियों द्वारा बम्बई (मुम्बई) में मुद्रण की विस्तृत व्यवस्था की गई थी। पहला भारतीय भाषा का समाचार पत्र दिग्दर्शन सन् 1818 में बंगाल में प्रकाशित किया गया था। भारत में सन् 1822 में लिथोग्राफी द्वारा मुद्रण प्रारम्भ किया गया था। प्रथम लिथोग्राफी प्रेस की स्थापना कोलकाता में की गई थी। पटना भी लिथोग्राफी द्वारा मुद्रण का प्रारम्भिक केन्द्र रहा है। यहां पर चित्रकार सर चार्ल्स डी. ओलेप ने बिहार लिथोग्राफी प्रेस की स्थापना अपने द्वारा बनाये चित्रों को मुद्रित करने के लिये की थी। इन्होंने स्थानीय चित्रकार जयरामदास को लिथोग्राफी में प्रशिक्षित किया और अपना सहायक बनाया था। सन् 1820 से 1850 के मध्य तक कोलकाता में बहुत अधिक लिथोग्राफी प्रेसों की स्थापना हो चुकी थी और लिथोग्राफी तकनीक द्वारा चित्रों का मुद्रण किया जाने लगा था। 30 मई, 1826 को हिन्दी का पहला समाचार-पत्र उदन्त मार्तण्ड कोलकाता से प्रकाशित किया गया। उस समय छपने वाले अधिकतर विज्ञापन वर्गीकृत व घोषणाएँ होती थीं जो विदेशी वस्तुओं के लिए अधिक होते थे जैसे- टोप, जूते, कपड़े और पनीर आदि जिनमें भाषा पर अधिक ध्यान नहीं दिया जाता था। उनकी भाषा काम-चलाऊ होती थी। उस समय भागे हुए लड़कों के बारे में भी विज्ञापन छपते थे, जैसे-31 मई 1887 को कलकत्ता गजट में भागे हुए लड़के के बारे में विज्ञापन छपा था जिसमें उसके बारे में जानकारी थी एवं उसको खोज कर लाने वाले को एक सोने की मोहर (मुद्रा) देने के बारे में लिखा गया था किन्तु उसकी भाषा काम-चलाऊ थी। 21 नवम्बर 1888 में मुम्बई से दी टाइम्स ऑफ इण्डिया में दो विज्ञापन मुद्रित हुये जो खाने के सामान से सम्बन्धित थे। उस समय अधिकतर विज्ञापन विदेशी आयातित वस्तुओं के होते थे।

भारत में सन् 1890 में छपने वाले विज्ञापनों में लगभग 50 प्रतिशत विज्ञापन तो एलोपेथिक दवाओं के ही होते थे जिनकी भाषा अंग्रेजी होती थी। ये विज्ञापन 'टाइम्स ऑफ इण्डिया' व 'ट्रिब्युन' में छपते थे। उस समय आयुर्वेदिक दवाओं के विज्ञापन मुम्बई समाचार-पत्र में छपते थे। संस्कृत और फारसी भाषा से अंग्रेजी में अनुवादित पुस्तकों, जैसे-भगवद्गीता, उत्तर रामचरित तथा आइने अकबरी आदि के विज्ञापन भी समाचार पत्रों में सम्मानजनक स्थान लिए हुए होते थे। 19 वीं सदी के अन्त तक कोलकाता का बाजार तेजी से विकसित हो रहा था और इसमें ग्रामोफोन, साइकिल एवं बैंक आदि सम्बन्धी सेवायें उपलब्ध होने लगी थी।

भारत में 20 वीं शताब्दी के आरम्भ में विज्ञापन का आधुनिक स्वरूप सामने आया। कुछ समाचार पत्रों, जैसे-स्टेट्समेन और टाईम्स ऑफ इण्डिया ने विज्ञापनदाताओं को कला सम्बन्धी, कॉपी लेखन के लिए सेवायें देना प्रारम्भ किया। उस समय के विज्ञापनों में स्वदेशी पर जोर दिया जाने लगा था जिसका उद्देश्य भारतीय उत्पादों के प्रति जागरूकता लाना था। उस समय दिल्ली की हिन्दू बिस्कुट कम्पनी ने अपने विज्ञापनों में कहा कि उनके द्वारा बनाये गये बिस्कुट आयातित बिस्कुटें से अधिक ताजा, पौष्टिक व सस्ते हैं। इसी तरह सन् 1906 में धारीवाल कम्पनी द्वारा प्रसारित किये गये विज्ञापन का मुख्य शीर्षक था- 
"भारत में बना भारत का" जो कि ऊनी वस्त्रों के लिए किया गया विज्ञापन था। उस समय स्वदेशी निब, स्वदेशी होल्डर, स्वदेशी दवाइयाँ आदि के विज्ञापन भी प्रसारित किये जाते थे। रेलवे, बैंकिग सेवा तथा शेयर बाजार के उदय ने भी विज्ञापन को बढ़ावा दिया। सन् 1907 में भारत में रोटेरी मशीन के आ जाने के बाद सबसे पहले कलकत्ता से प्रकाशित होने वाले समाचार-पत्र स्टेट्समेन ने इस मशीन का प्रयोग शुरू किया और बाद में अन्य समाचार-पत्रों ने भी इस मशीन का उपयोग करना प्रारम्भ कर दिया जिससे पत्र-पत्रिकाओं की छपाई सस्ती व अधिक संख्या में होने लगी। अब अधिक संख्या में लोग समाचार पत्र एवं पत्रिकाएं पढ़ने लगे और इनमें विज्ञापनों की संख्या भी बढ़ी। उस समय कोलकाता देश की राजनीतिक राजधानी और मुम्बई देश की औद्योगिक राजधानी थी। इसलिए विज्ञापन उद्योग का प्रारम्भ भी इन्हीं केन्द्रों पर हुआ।

सन् 1907 में पहली भारतीय विज्ञापन एजेन्सी की स्थापना मुम्बई में हुई। सन् 1909 में कोलकाता में विज्ञापन एजेन्सी की स्थापना हुई। ये विज्ञापन एजेन्सियाँ कला सम्बन्धी सेवायें भी देने लगी थीं। भारत में टाइम्स ऑफ इण्डिया ने 1910 ई. में अपने वार्षिक अंक में प्रथम रंगीन विज्ञापन मुद्रित किये जो पियर्स साबुन तथा इनो फ्रूट नमक से सम्बन्धित थे।

प्रथम विश्व युद्ध के समय समाचार-पत्रों की प्रसार संख्या में बढ़ोतरी हुई, जिसके कारण समाचार-पत्रों की संख्या भी बढ़ी। विश्व युद्ध के पश्चात् भारतीय बाजारों में विदेशी वस्तुएं बहुतायत में आने लगी और विदेशी निर्माताओं के लिए भारत एक बड़े बाजार के रूप में सामने आया। बाजार में वस्तुओं की अधिकता के कारण प्रेस में विज्ञापनों की संख्या भी बढ़ने लगी और इसी समय विज्ञापन के लिए बाह्य माध्यम होर्डिंग, कियोस्क आदि अन्य माध्यमों का प्रयोग प्रारम्भ हुआ।

सन् 1920 के आसपास कुछ विदेशी विज्ञापन एजेन्सियों ने भी देश में अपनी शाखाओं की स्थापना की। आजादी से पहले अधिकतर विज्ञापन कार, ग्रामोफोन, होटल और कपड़ों आदि से सम्बन्धित होते थे जो राजघराने के लोगों, अंग्रेजों और अमीरों के लिए प्रसारित किये जाते थे। सन् 1931 में विज्ञापन एजेंसी ने आधुनिक एजेंसी के रूप में काम प्रारम्भ किया। दूसरे विश्वयुद्ध के समय अंग्रेज सरकार द्वारा भी भारतीय लोगों का सहयोग प्राप्त करने के लिए विज्ञापन अभियान चलाये गये थे। अनेक विज्ञापनों में राष्ट्रीय नेताओं द्वारा दिये गये वक्तव्य भी छापे जाते थे। उस समय फिल्मों के अलावा अन्य विज्ञापनों में मॉडल के रूप में जो चित्र छपते थे उनमें भारतीय महिलाओं के चित्र नहीं होते थे। विदेशी महिलायें ही मॉडल के रूप में कार्य करती थीं हालांकि पुरूष मॉडल भारतीय ही होते थे। सन् 1939 में इण्डियन एण्ड ईस्टर्न न्यूज पेपर एसोसिएशन का गठन किया गया और 1945 ई. में एडवरटाइजिंग एसोसिएशन ऑफ इण्डिया की स्थापना हुई और इसके साथ ही समाचार पत्रों एवं पत्रिकाओं में छपने वाले विज्ञापन आकर्षक एवं प्रभावी दिखाई देने लगे।

1 जुलाई 1941 को संयुक्त राज्य अमेरिका में प्रथम टेलीविजन विज्ञापन का प्रसारण हुआ था। घड़ीसाज बुलोवा ने एक विज्ञापन प्रस्तुत करने के लिए 9 डालर का भुगतान किया था। 10 सेकंड वाले एक स्पॉट में संयुक्त राज्य अमेरिका के एक नक्शे पर रखी एक दीवार की घड़ी की तस्वीर दिखाई गई जिसके साथ "अमेरिका रूस ऑन बुलोवा इन टाइम" की आवाज गूंजी थी $I^{1} / 221$ सितम्बर 1955 को आईटीवी पर यूके में प्रथम टीवी विज्ञापन का प्रसारण किया गया था। इसमें गिब्स एसआर टूथपेस्ट का विज्ञापन दिया गया था। 1990 के दशक के शुरू में टेलीविजन विज्ञापन का खर्च केवल महत्वपूर्ण निवेश करने की इच्छुक बड़ी कंपनियां ही उठा सकती थीं। लेकिन डेस्कटॉप
वीडियो के आगमन ने कई छोटे और स्थानीय कारोबारियों को स्थानीय केबल टेलीविजन सेवाओं पर टीवी विज्ञापन प्रसारण करने का अवसर प्रदान किया।

कई विज्ञापनों में आकर्षक वाक्यांश होते हैं। आकर्षक गीत या धुन होते हैं। विज्ञापन अभियान समाप्त होने के बाद भी दर्शकों के मन पर इसका प्रभाव चलता रहता है। अनवरत् वे विचार मन को झकझोरते रहते हैं। अर्थात् इस तरह से उन्हें प्रस्तुत किया जाता है कि वे विज्ञापन उनके मन में जगह बना लेते हैं। एक उदाहरण-1950 के दशक से 1970 के दशक तक। इतने लम्बे समय तक विंस्टन सिगरेट्स का प्रचार अभियान चलाया जाता है। उसके प्रचार का एक वाक्य है-“विंस्टन टेस्टस गुड लाइक ए सिगरेट शुड।" अर्थात् विंस्टन का स्वाद उतना ही बेहतर है जितना एक सिगरेट को होना चाहिए। एक और वाक्यांश"व्हेयर्स द बीफ"? यह बहुत लोकप्रिय हुआ था। यह वाक्य इतना लोकप्रिय हुआ कि इसका प्रयोग वॉल्टर मोंडेल ने 1984 के राष्ट्रपति पद के चुनाव में कर डाला। एक और लोकप्रिय प्रचार"आई हैव फालेन एण्ड आई कांट गेट अप।" अर्थात् मैं गिर गया हूं और मैं उठ नहीं सकता। इस विज्ञापन का इस्तेमाल दो दशक पहले हुआ था। कुछ विज्ञापन एजेंसी अधिकारियों ने एक से अधिक स्थायी नारों को जन्म दिया है। कुछ मशहूर नारों को जन्म देने का श्रेय 'मैरी वेल्स लॉरेंस' को जाता है। "आई लव न्यूयॉर्क।" "ट्रस्ट दी मिडास टच" (मिडास के स्पर्श वाली कहानी पर यकीन करें) "रेज योर हैंड इफ यू आर स्योर" अर्थात् अगर आपको विश्वास है तो अपना हाथ उठाएं। इन विज्ञापनों का इस्तेमाल आज भी किया जाता है।

विज्ञापनों में एनीमेशन का इस्तेमाल किया जाता है। ऐसा करने से विज्ञापनों में आकर्षण पैदा हो जाता है। ऐसा आकर्षण केवल उत्पादों या कलाकारों से प्राप्त करना आसान नहीं है। यूके में यादगार टीवी विज्ञापनों के लिए शीर्ष स्थान प्राप्त करने वाले विज्ञापनों में एनीमेशन शामिल है। जैसे-क्लासिक रम्मेश और क्रिएचर कम्फर्ट्स विज्ञापन। जैसे-आईटीवी ${ }^{3}$ या चैनल ${ }^{4}$ पर। एक विज्ञापन है, बैटरी से चलने वाले खरगोशों का। एक कमरे में कई खरगोशों को ड्रम बजाते हुए दिखाया गया। एनर्जाईजर बेटरी वाला खरगोश बाकी सभी खरगोश को छोड़कर अपना ड्रम बजाता जा रहा था और बाकी खरगोस धीरे-धीरे कमजोर पड़ते जा रहे थे। एनाउंसर कहती है- चलता ही जा रहा है। अभी भी चलता जा रहा है। यह है, एनर्जाईजर बैटरी कम्पनी का तरीका। अन्य प्रमुख बैटरियों की तुलना में एनर्जाईजर बैटरी अधिक समय तक चलती है। यह विज्ञापन अभियान लगभग 15 साल तक चलता रहा। अर्थात् यह विज्ञापन सफल रहा।

कार्यक्रमों के बीच में टीवी विज्ञापन दिखाई देते हैं। थोड़े-थोड़े अंतरालों पर विज्ञापन हस्तक्षेप करते रहे हैं। आज रिमोट कन्ट्रोल से विज्ञापन आने के समय दर्शक आवाज को बंद कर देता है या चैनल बदल देता है। यह भी देखा जाता है कि दर्शक विज्ञापनों के दौरान दूसरे कामों में लग जाता है। अतः विज्ञापन उद्योग इस काम पर अधिक नजर गड़ाए हुए है कि दर्शकों के मन में विज्ञापनों के प्रति इतनी रूचि भर दी जाय कि वे विज्ञापनों का बेसब्री से इंतजार करें।

विज्ञापनों के प्रसारण में कार्यक्रमों का कुछ समय चला जाता है। कामर्शियल ब्रेक भी अब अधिक लम्बे हो गए हैं। 1960 के दशक में अमेरिकी टीवी कर्यक्रम का यदि एक घंटे का समय था तो विज्ञापनों को छोड़कर 51 मिनट तक हीं चलता था। आजकल 42 मिनट तक हीं चलता है। अर्थात् अठ्ठारह मिनट विज्ञापन में चला जाता है। यदि 30 मिनट का काई कार्यक्रम है तो वह कार्यक्रम 22 मिनट तक हीं चलेगा और शेष समय विज्ञापन का होगा $\left.\right|^{5}$ 
आमतौर पर विज्ञापनदाता 18-49 वर्ष के लोगों को अपना निशाना बनाना चाहते हैं जो दर्शक बूढ़े हो चुके हैं, उन्हें विज्ञापन में कोई रुचि नहीं होती है। वे अपने खरीदने की आदतों को बदलना नहीं चाहते हैं। ${ }^{6}$

हाल के वर्षों से यह जानकारी प्राप्त हुयी है कि युवा पुरुष महिलाओं की तुलना में कम टीवी देखते हैं। अतः विज्ञापनदाता यह चाहते हैं कि युवा महिलाओं को अधिक से अधिक प्रभावित किया जाय। अर्थात् युवा महिलाओं को ध्यान में रखकर विज्ञापन द्वारा उन पर फोकस किया जाय $\mathrm{P}^{7}$ ऐसा करना विज्ञापनदाताओं के लिए अधिक फायदेमंद हो सकता है।

कई टीवी विज्ञापनों को इतना सजाकर प्रस्तुत किया जाता है कि उन्हें तीस सेकंड चलने वाली छोटी फिल्म माना जा सकता है। इसलिए कई फिल्म निर्देशक एक्सपोजर पाने और पैसा कमाने के एक साधन के रूप में टीवी विज्ञापनों का निर्देशन करते हैं। ऐसा देखा गया है कि कई विज्ञापन कभी-कभी दिखाई देता है, फिर भी वह मशहूर हो जाता है। सुपरिचित हो जाता है और उसे एक क्लासिक टीवी क्षण माना जाने लगता है।

कई विज्ञापन बहुत लोकप्रिय हो जाते हैं। इसके बावजूद दर्शकों की एक बड़ी संख्या विज्ञापनों को एक मुसीबत समझते हैं। विज्ञापनों की संख्या काफी बढ़ती जा रही है। एक हीं विज्ञापन को जरूरत से ज्यादा दिखाना परेशानी का कारण बन गया है। टीवी विज्ञापन का मुख्य माध्यम है। अब व्यापारी यह चाहता है कि अपने प्रोड्क्ट को बेचने के लिए विज्ञापन अभियान का हिस्सा बना जाय। इसलिए कमर्शियल ब्रेक अब लम्बे होते जा रहे हैं। विज्ञापन अभियान के कारण एवं विज्ञापनों की वजह से कार्यक्रमों में कटौती की जाने लगी है। कथानक में बदलाव कर दिया जाता है। ऐसा भी देखा जाता है कि कई विज्ञापनों की ध्वनि बहुत ज्यादा होती है। यूनाइटेड स्टेट्स कांग्रेस ने विज्ञापनों के आवाज को कम करने के लिए 30 सितम्बर 2010 को काम अधिनियम नामक एक विधेयक पास किया गया। यूके में ब्रॉडकास्टिंग कमिटि ऑफ एडवरटाइजिंग प्रैक्टिस का भी यही नियम है।

यूके में 22 सितम्बर 1955 को पहला विज्ञापन दिखाया गया। वह टूथपेस्ट के लिए दिया गया पहला विज्ञापन था।

फ्रांस में सार्वजनिक चैनलों के लिए 8 बजे शाम के बाद विज्ञापन दिखाने की मनाही है।

आयरलैण्ड गणराज्य में आयरलैण्ड प्रसारण आयोग सभी प्रसारकों को हर घंटे ज्यादा से ज्यादा 10 मिनट तक विज्ञापन दिखाने की अनुमति है $\left.\right|^{8}$

डेनमार्क में डेनिश डीआर चैनलों को एक टीवी लाइसेंस द्वारा वित्तपोषित किया जाता है। इसलिए वे विज्ञापन नहीं दिखाते हैं। अन्य डेनिश टीवी नेटवर्क टीवी-2 केवल कार्यक्रमों के बीच के खण्डों में विज्ञापन दिखाते हैं। अगले कार्यक्रम के समय के आधार पर इसमें 2 से 10 मिनट लग सकता है। डेनमार्क में कमर्शियल ब्रेकों पर सख्त प्रतिबन्ध है और बच्चों को लक्ष्य बनाकर बनाया गया विज्ञापन प्रतिबंधित है।

आस्ट्रेलिया दुनिया के कुछ देशों में से एक है जहां किसी कार्यक्रम से पहले और उसके बीच में और समापन के समय विज्ञापन दिखाई दे सकते हैं। आस्ट्रेलिया में टीवी विज्ञापनों पर कुछ प्रतिबन्ध है। जैसे-सिगरेट का विज्ञापन पूरी तरह प्रतिबन्धित है। छोटे बच्चों के लिए जो कार्यक्रम बनाए और दिखाये जाते हैं, उस दौरान विज्ञापन दिखाए जाने पर प्रतिबंध है।

न्यूजीलैंड- चाहे राज्य के स्वामित्व में हो या निजी, न्यूजीलैंड के सभी टीवी चैनल हरेक घंटे में औसत 15 मिनट तक विज्ञापन दिखाते हैं। आधे घंटे चलने वाले कार्यक्रम में आम तौर पर दो
और एक घंटे चलने वाले कार्यक्रम में चार विज्ञापन ब्रेक लिए जाते हैं। क्रिसमस दिवस, गुड फ्राइडे, ईस्टर रविवार और दोपहर से पहले रविवार की सुबह को भी टीवी विज्ञापनों पर प्रतिबन्ध लगा दिया गया है। शराब, तम्बाकू और सेहत को नुकसान पहुंचाने वाले अस्वास्थ्यकर खाद्य पदार्थों पर प्रतिबन्ध है। दक्षिण कोरिया में मौजूदा नियमों के तहत स्थानीय चैनल कार्यक्रम के बीच में कमर्शियल ब्रेक नहीं ले सकते हैं। विज्ञापनों को आमतौर पर कार्यक्रम के परिचय और आरम्भ के बीच और कार्यक्रम के अंतिम भाग और अंत के बीच दिखाया जा सकता है।

इसप्रकार कई देशों में सिगरेट के विज्ञापनों पर प्रतिबन्ध है। टीवी कार्यक्रमों किसी हार्ड ड्राइव में रिकॉर्ड करने की अनुमति देने वाले टिवो जैसे डिजिटल वीडियो रिकार्डरों जिन्हें डीटीआर के नाम से भी जाना जाता है। अर्थात् डिजिटल टीवी रिकॉर्ड। स्काई+डिश नेटवर्क और एस्ट्रो मैक्स जैसी सेवाएं शुरू होने से दर्शकों को रिकॉर्ड किए गए कार्यक्रमों के विज्ञापनों को हटाने या छोड़ने का विकल्प दे दिया है।

2008 के अंत में यूके के 22 प्रतिशत परिवारों के पास डीटीआर था। इनमें से ज्यादातर परिवारों के पास स्काई+ था। इन घरों में मिले आंकड़ों (स्काईव्यश के 33,000 से अधिक पैनल के माध्यम से एकत्रित) से पता चलता है कि किसी भी घर में डीटीआर आ जाने से उस परिवार के लोग 17 प्रतिशत ज्यादा टीवी देखते हैं। इसप्रकार प्राचीन ऐतिहासिक काल में शिलालेख ही विज्ञापन के रूप होते थे। किसी अंश तक शिलालेखीय सन्देशों को विज्ञापन कहा जा सकता है, परन्तु आधुनिक सन्दर्भ में उन्हें विज्ञापन कहना अतिशयोक्तिपूर्ण है। वह सामान्यतः प्रचार कार्य के प्राचीन रूप हैं जिसका कार्य मात्र जानकारी देना था, उसमें किसी ऐसी प्रतिक्रिया की अपेक्षा नहीं थी जिससे व्यक्तिगत अथवा व्यापारिक फायदा हो। 'विज्ञापन' का इस्तेमाल यूनान के प्रारम्भिक लोकतंत्रों के चुनावों में मौखिक रूप में किया गया। मौखिक प्रचार को भी विज्ञापन के आधुनिक अर्थ में विज्ञापन नहीं माना जा सकता। निश्चय ही वह विज्ञापन का ही रूप था, परन्तु यह मात्र प्रचार का लोकतांत्रिक रूप ही रहा होगा जो एक सार्वजनिक अभिव्यक्ति का साधन मात्र था। यह कार्य आज भी संचार माध्यमों के माध्यम से किया जाता है, जिसे विज्ञापन की संज्ञा नहीं दी जाती। यह भी प्रचार ही है जो सार्वजनिक हित के उद्देश्य से किया जाता है। इस तरह से प्रचार को अगर विज्ञापन की श्रेणी में रखा जाय तो भारत में यूनान से भी पहले गणतन्त्रों के अस्तित्व के ऐतिहासिक विवरण प्राप्त होते हैं। निश्चय ही प्रचार वहाँ भी होता होगा, अतः ऐतिहासिक रूप में भारत में बहुत समय पहले 'विज्ञापन' किया जाता था, परन्तु वास्तविक बात यह है कि इन अवसरों पर किया जाने वाला प्रचार कार्य विज्ञापन का रूप नहीं था।

आधुनिक शैली का विज्ञापन स्वरूप सन् 1440 ई. में मैउज, जर्मनी में गुटेनवर्ग के माध्यम से मुद्रण यन्त्र के आविष्कार से मुद्रित विज्ञापनों की परम्परा आरम्भ हुई। लन्दन के ब्रिटिश म्यूजियम में रखे मिस्र के एक विज्ञापन को विश्व का सबसे पहले प्रकाशित विज्ञापन माना जाता है। इस विज्ञापन में एक भाग हुए दास को लाने की बात कही गई है। सन् 1480 ई. में पहली बार विलियम कैक्ट्स ने एक धार्मिक पुस्तक का विज्ञापन एक पत्रिका में प्रकाशित कराया था सन् 1650 ई. में इंग्लैण्ड के समाचार-पत्रों एवं पत्रिकाओं में नियमित रूप से चाय, काफी आदि के विज्ञापन नियमित रूप से छपने लगे। सोलहवीं सदी में 'लन्दन गजट' के परिशिष्ट रूप में छपे भाग में मात्र विज्ञापनों का ही प्रकाशन किया गया था।

विश्व को मुद्रण क्रान्ति ने समाचार-पत्रों के रूप में जहाँ एक ओर वैचारिक क्रांति प्रदान की थी, वहीं दूसरी ओर विज्ञापन क्रान्ति ने 
प्रचार के वैयक्तिक क्षेत्र को भी सुनहरे अवसर प्रदान कर दिये थे। विज्ञापन कार्य स्वयं में एक अलग व्यवसाय बन गया। समाचार-पत्रों की प्रसार संख्या के आधार पर विज्ञापन मूल्यों का निर्धारण किया गया। विज्ञापन करने वाली विश्व की सबसे बड़ी न्यूयार्क की जे.वाल्टर थामसन कम्पनी है, इसने सन् 1971 ई. में विज्ञापन के बीच के चार रंगीन पृष्ठों के लिये 98200 डालर दिये। विश्व का सबसे सुन्दर विज्ञापन 4 जुलाई, 1925 ई. फ्रांस की एफ्लाटावर पर इलेक्ट्रिक सिट्रोन कम्पनी ने दिया। यह विज्ञापन ढाई लाख छोटे बल्बों एवं 58 मील लम्बे तारों से तैयार किया गया था, जो 25 मील दूर से देखा जा सकता था।

भारत में सबसे पहली विज्ञापन संस्था सन् 1905ई. में कलकत्ता में स्थापित हुई जिसका नाम वी.दत्ताराम एण्ड कम्पनी था। सन् 1925ई. में सेण्ट्रल पब्लिसिटी सर्वस कलकत्ता में ही स्थापित हुई। मद्रास में एल.आर.एडवटाईजिंग एवं अहमदाबाद में कृष्ण पब्लिसिटी कम्पनी, कानपुर में जुपीटर पब्लिसिटी कम्पनी आदि की सथापना हुई। स्वतंत्रता से पहले भारत में लगभग 60 विज्ञापन कम्पनियाँ स्थापित हो चुकी थी। आजकल इनकी संख्या पांच सौ से ज्यादा हो गई हैं। 15 नवम्बर, 1967 से विविध भारती की स्थापना से आकाशवाणी के माध्यम से विज्ञापन प्रसारित किये जाने लगे। 1 जनवरी, 1987 से दूरदर्शन ने भी विज्ञापन सेवा आरंभ की थी। निश्चित रूप से वर्तमान युग में विज्ञापन एक सामाजिक जरूरत बन चुकी है। वैज्ञानिक क्षेत्र में क्रान्तिकारी प्रगति ने विज्ञापन क्षेत्र में भी क्रान्ति ला दी है। दैनिक पत्र-पत्रिकाओं, आकाशवाणी, दूरदर्शन, दीवारों, होर्डिंग, आकाशीय अक्षर लेखन, प्रचार, उद्घोषणाओं, डाक के माध्यम से भेजे जाने वाले पत्रों का व्यावसायिक दुनिया से एक अटूट विज्ञापन सम्बन्ध स्थापित हो चुका है।

\section{संदर्भ सूची :}

1. http://www.bulova.com./about/history aspx.

2. A.U.S. Television chronology, 1875-1970 jeff560.tripod.com. अभिगमन तिथि 2009-08-19

3. बेटस एवर एडवरटाइज प्राप्त किया गया -30.07 .2010$

4. 100 ग्रेटेस्ट टीवी एड्स, 30.07 .2010 को प्राप्त किया गया।

5. हाउ मच डू टेलीविजन एड्स कॉस्ट?

6. Storey, Michael (23-4-2009) The TV column: Not in 18-49 age group? TV excess write you off's Arkansas Democrate Gazette. अभिगमन तिथि 02-05-08

7. http: /www.koeppeldirect.com/03/08 advertisingfemale-demographic.htm

8. Broadcasting Commission of Ireland. "Radio and Television Act. 1988".

9. अभिगमन तिथि 28-01-2009 